\title{
Chronic Pain, Mood Disorders and Substance Use: Outcomes of Interdisciplinary Care in a Residential Psychiatric Hospital
}

This article was published in the following Dove Press journal: Journal of Pain Research

\author{
Frank D Buono' \\ Seddon R Savage ${ }^{2}$ \\ Brianna Cerrito (D) $^{3}$ \\ Julianne O'Connell ${ }^{3}$ \\ Amir Garakani (D) ${ }^{1,3}$ \\ Sigurd Ackerman (iD ${ }^{3}$ \\ Christopher J Cutter ${ }^{4}$ \\ 'Department of Psychiatry, Yale School of \\ Medicine, New Haven, CT, USA; \\ ${ }^{2}$ Department of Anesthesiology, Geisel \\ School of Medicine at Dartmouth, \\ Hanover, NH, USA; ${ }^{3}$ Silver Hill Hospital, \\ New Canaan, CT, USA; ${ }^{4}$ Yale Child Study \\ Center, Yale University School of \\ Medicine, Yale University, New Haven, \\ CT, USA
}

Purpose: The objective is to report outcomes of an interdisciplinary group-based residential chronic pain recovery program (CPRC), located in a private non-profit psychiatric hospital. The chronic pain program was aimed at treatment and engagement in self-care of both pain and co-occurring disorders in a residential facility that also offered treatment for specific psychiatric disorders.

Patients and Methods: A retrospective chart review was conducted that included a convenience sample of 131 patients admitted from March 2012 through August 2017 who completed treatment. An interdisciplinary team of professionals provided psychobehavioral therapy, movement therapies and medication management. Patients completed a battery of psycho-social and demographic questionnaires on admission and before discharge of the program.

Results: Significant differences were noted in pain severity, pain interference, depression and anxiety $(\mathrm{p}<.01)$ between admission and discharge, and the Chronic Pain Coping Inventory demonstrated significant differences in guarding $(p<.001)$, asking $(p=.018)$, exercise $(\mathrm{p}<.001)$, relaxation $(\mathrm{p}<.001)$, and pacing $(\mathrm{p}=.024)$. Of patients using opioids on admission, at discharge, $37 \%$ had tapered and remained off all opioids, $43 \%$ were using buprenorphine for opioid use disorder, and 20\% continued on analgesic opioids.

Conclusion: Treatment was associated with reductions in pain severity and interference, in anxiety and in depression as well as improvements in pain coping. Additionally, there was a reduction in reliance on opioids for pain relief.

Keywords: interdisciplinary care, chronic pain management, residential treatment, medication management, psychosocial therapy

\section{Introduction}

Chronic pain is estimated to affect 100 million adults in the United States. ${ }^{1}$ It is a significant public health problem that costs the United States between $\$ 560$ to $\$ 635$ billion, with a value of lost productivity ranging from $\$ 299$ to $\$ 334$ billion. ${ }^{2,3}$ Chronic pain is an unpleasant sensory and emotional experience, ${ }^{4,5}$ and can be difficult to treat as the experience itself is subjective to the individual. ${ }^{6-9}$ Chronic pain often co-occurs with mental health disorders such as depression, anxiety, and/ or substance use disorders which may complicate its treatment. ${ }^{7-10}$ However, cooccurring disorders are often not diagnosed, and even when identified, are often not effectively addressed and can therefore be substantial barriers to successful pain treatment. ${ }^{11,12}$ Such comorbid diagnoses can reduce an individual's quality of life
Correspondence: Frank D Buono

$\mathrm{Tel}+\mathrm{I}-203-9372309 * 118$

Fax + I-203-6040542

Email frank.buono@yale.edu
Journal of Pain Research 2020:13 1515-1523

1515 
and increase somatic symptom severity ${ }^{3,13}$ as well as short-term mood changes, and sleep disruption. ${ }^{14}$

Interdisciplinary care that addresses the diverse biopsychosocial dimensions of chronic pain has been recognized as the gold standard of care of chronic pain for decades. ${ }^{15,16}$ Yet, there are numerous health system barriers that prevent the implementation of interdisciplinary care. ${ }^{17}$ Medication management, including widespread use of opioids, has dominated pain care in recent years. ${ }^{7,18,19}$ While opioid prescriptions have fallen almost a third from their peak in 2011, opioids are still prescribed at a rate eight times higher than in $1999 .{ }^{20}$ The increased clinical availability of opioid medications has also been associated with increased medication misuse, diversion, addiction and overdoses; moreover, evidence of the long-term effectiveness of opioid medications in the treatment of chronic pain is inconclusive. ${ }^{18,21}$ In addition, opioids often mask chronic pain symptomology without addressing the root cause of pain. ${ }^{22}$ With recent attention to the challenges associated with widespread use of opioids, there has been renewed interest in interdisciplinary care. Few studies have methodically examined the impact of such care on pain, pain interference in function, psychiatric co-morbidity and opioid use. ${ }^{23,24}$ This paper will report outcomes of an interdisciplinary residential chronic pain program aimed at treatment of both pain and co-occurring disorders in a private residential facility that also offered inpatient treatment for specific psychiatric disorders.

\section{Patients and Methods Study Population}

This retrospective chart review included patients admitted from March 2012 through August 2017 who completed treatment. The program was a minimum 28 -day residential program with a maximum census of eight patients, located within a psychiatric hospital in New Canaan, Connecticut. Patients were admitted for a complaint of chronic pain with or without co-occurring mental health or substance diagnoses. The program focused on acquisition of selfmanagement skills with goals to reduce pain, improve coping with residual pain, increase function, manage mood, effectively treat co-occurring disorders (mental health or addiction), reduce medication reliance, and enhance overall quality of life.

The authors conducted a retrospective review following the Gearing, Mian, Barber, and Ickowicz ${ }^{25}$ method for conducting a convenience sampling protocol retrospective chart review. A convenience sampling method was elected over quota or systematic sampling given its greater sensitivity to changes over time and reduction of response bias. During the selected time period, 256 patients had been admitted to the program. Of the 256 patients, 131 patients' medical charts were extracted representing $51 \%$ of the total sample. Documentation of the following criteria was necessary for inclusion of the study: 1) Psychiatric diagnosis upon admission, if any; 2) Self-reported pain severity at admission and discharge and pain duration in number years; 3) Opioid medication use, if any, at admission and discharge in morphine milliequivalents (MSEq) and 4) Completion of the 28-day program.

\section{Program and Treatment}

The program was a 28-day residential program within a psychiatric treatment facility that included an on-site inpatient unit and six other residential programs including eating disorders, women's and men's substance use disorders to dual diagnoses programs, adolescent programs, dialectical behavior therapy, and thought disorders. All patients in the CPRC program participated at the minimum five days a week of individuals or group psychotherapy. Therapies included 1) cognitive-behavioral therapy (CBT) to comprehensively address pain, mood and substance use disorders; 2) groupbased mindfulness strategies including meditation, body awareness, gratefulness; 3) PT supervised physical therapy tailored to individual condition; 4) land-based exercise (aerobic, stretch, strengthening); 5) Aquatic exercise; 6) goal setting and process groups; and 7) education on pain, mood, substance use, sleep hygiene, nutrition, and related topics. Patients also participated in community-based 1) 12-step groups including Chronic Pain Anonymous, AA, NA; 2) Movement groups including yoga, Tai Chi, Chi Gong; 3) Art therapy; and 4) Family programs. All interventions were conducted by licensed practitioners in their respective disciplines (ie, psychologists, physical therapists, marriage family therapists).

Treatment was primarily group-based but included individual counseling sessions with a psychologist a minimum of twice weekly, individual PT sessions at least weekly, and medical/psychiatric appointments from 1 to 5 times a week as indicated. The schedule of therapeutic activities was intensive. Weekday mornings included meditation and goal setting, one hour of gym exercise and one hour of water-based therapy; afternoons included three hours of psychotherapy or education sessions plus individual meetings; and evenings included at least one hour of movement 
or self-help group. On weekends, patients engaged in similar activities on a less intensive basis. The residence was staffed by residential counselors trained to provide support for positive change between formal treatment sessions.

Medication management was individualized by the patient's treating psychiatrist. Medications for anxiety, depression or other psychiatric conditions as well as nonopioid medications for pain were adjusted as clinically indicated based on the patient's presentation and the clinical judgment of the physician. This could include adjusting or eliminating admission medications or introducing new medications. All patients using opioids on admission were encouraged to engage in a trial taper of opioids in order to better understand how opioids impacted their experience of pain and to help determine next steps with respect to opioid management. Tapers were individualized with a goal of permitting each patient to remain actively engaged in the program while tapering. Based on the response to trial taper, options for ongoing opioid management included: no use of opioids, transition to opioid agonist therapy for OUD, or continuation of opioid analgesic therapy, often at a lower dose or rotated to a new opioid, depending on identified comorbidities and responses to trial opioid taper. In the few patients on opioid agonist therapy for opioid use disorder (OUD) at admission, medications were either continued or transitioned to alternative OUD medication.

The study was initially reviewed and approved by the Institutional Review Board at the Yale School of Medicine on October 10, 2017 (IRB\# 2,000,021,764). No consent was needed as the current study was a retrospective analysis to review their medical records, thus allowing for a waiver of consent. All patient data were confidential and complied with the Declaration of Helsinki.

\section{Assessments}

Several validated assessments were administered at intake and discharge to evaluate change, and to be utilized by the clinical team to inform care. Brief Pain Inventory-Short Form (BPI-SF) ${ }^{26}$ is a self-report Likert and open-ended survey to assess pain severity (worst, least, average and right now) and interference in seven areas (mood, physical activity, work, social activity, relations with others, sleep, and enjoyment of life). The scores range from 0 to 10 with higher scores indicating worse pain and lower scores indicating little to no pain. For pain interference and severity, all questions within each sub-category were aggregated and averaged. The reliability, construct validity, and sensitivity to changes over time have been validated in various studies assessing chronic pain. ${ }^{27}$

Beck Depression Inventory-II (BDI-II) ${ }^{28}$ is a 21 -question self-report assessment that assesses the intensity of depression based on the DSM-IV criteria. The BDI-II is considered the gold-standard assessment for depression and has shown very good reliability (Cronbach's alpha $=0.92$ ). Beck Anxiety Inventory (BAI) $)^{29}$ is a 21-question self-report assessment that assesses the descriptive of subjective, somatic, or panic-related symptoms of anxiety. Pain Catastrophizing Scale (PCS) ${ }^{30}$ is a 13-item self-report assessment that quantifies an individual's pain experience, and how they feel and think about pain.

Chronic Pain Coping Inventory $(\mathrm{CPCI})^{31}$ is a 70 -question self-report assessment evaluating how patients manage their pain symptoms across illness and wellness coping. The CPCI evaluates illness and wellness-focused coping strategies across multiple sub-domains (guarding, resting, asking for assistance, exercise, relaxation, task persistence, coping, pacing, and seeking social support). Raw scores are converted into aggregated T-scores based on the normalized sample population, and then plotted on visual profile. The profile is broken into three categories: Clinical, subclinical, and adaptive ranges. Cronbach's alpha score ranges from 0.71 to 0.89 depending on the specific population.

\section{Data Retrieval and Analysis}

Two graduate research assistants were trained by the lead investigator on conducting formal inter-observer agreement (IOA) procedures. A pre-established Microsoft Access system was created to collect and manage data, and both research assistants were asked to individually assess accuracy of the inputted data. To ensure the accuracy of the data collected, $60 \%$ of all inputted data was evaluated by the second reviewer. IOA was calculated by dividing the total number of agreements by the total sum of agreements plus disagreements and multiplying by $100 \%$. Agreements were defined as two observers evaluating the same response within each Microsoft Access cell. Total IOA for all evaluated observations was $99 \%$ with four disagreements.

Data on opioid use on admission and at discharge were extracted from admission and discharge medications lists. Admission medication lists, including opioids and opioid dosing, were documented through a combination of review of medication bottles brought in with the patient, check of relevant state prescription drug monitoring programs, records of referring clinicians and patient report. Morphine milligram 
equivalents of all opioids were calculated using the Center for Medicare and Medicaid Services (CMS) opioid oral morphine milligram equivalent (MME) Conversion Factor chart (https://www.cms.gov/Medicare/Prescription-DrugCoverage/PrescriptionDrugCovContra/Downloads/OralMME-CFs-vFeb-2018.pdf).

All statistical analyses were conducted on IBM SPSS version 24. Categorical variable characteristics were evaluated by using analysis of variance for continuous variables. Pair-wise t-tests were used to compare rates of the standardized assessments, ie, BPI, BDI, BAI, PCS, and CPCI at admission and discharge of the CPRC program. Adjustments were made for multiplicity, missing information, and recording error. Specific patient information was extracted from the chart: age, gender, tobacco usage, pain diagnosis, mental health disorders diagnoses (primary, secondary, and tertiary), and opioid misuse.

\section{Results}

Demographic and clinical variables of the pooled patients for the chart review are seen in Table 1. The median age of the current study was 47.6 years with a standard deviation of 13.5 years. Of the total population sampled, musculoskeletal issues were the majority of primary pain diagnoses, affecting 72\% ( $\mathrm{n}=95)$ individuals; of these $53 \%(\mathrm{n}=69)$ had axial (back or neck) pain and 19\% (25) had limbrelated musculoskeletal pain. It should be noted that $48 \%$ $(n=63)$ were treated for a combination (minimum of three categories) of the following: psychiatric disorders, substance use, and chronic pain. On average, patients reported seeking treatment for their pain symptoms for 11.8 years prior to admission.

\section{Pain, Pain Interference and Pain Coping}

Values of the Brief Pain Inventory-Short Form (BPI-SF) were evaluated for pain severity and interference at

Table I Admission Diagnoses and Demographics

\begin{tabular}{|c|c|c|c|c|c|}
\hline Demographics & $\mathbf{N}$ & Percentage & Demographics & $\mathbf{N}$ & Percentage \\
\hline Age (in Years) (SD) & \multicolumn{2}{|c|}{$47.6(13.5)$} & \multicolumn{3}{|l|}{ Initial Primary Psychiatric Disorder } \\
\hline Gender & & & Depressive State/Depression NOS & 72 & $55 \%$ \\
\hline Male & 68 & $52 \%$ & Anxiety State/Anxiety NOS & 47 & $36 \%$ \\
\hline Female & 63 & $48 \%$ & Posttraumatic Stress Disorder & 5 & $3 \%$ \\
\hline Ethnicity & \multirow{5}{*}{$\begin{array}{l}115 \\
5 \\
4 \\
7\end{array}$} & \multirow{5}{*}{$\begin{array}{l}88 \% \\
4 \% \\
3 \% \\
5 \%\end{array}$} & \multirow{4}{*}{$\begin{array}{l}\text { Bipolar I or II } \\
\text { No Diagnosis } \\
\text { Number of Patients with Two or More Psychiatric } \\
\text { Disorders }\end{array}$} & \multirow{4}{*}{$\begin{array}{l}4 \\
4 \\
116\end{array}$} & \multirow{4}{*}{$\begin{array}{l}3 \% \\
3 \% \\
89 \%\end{array}$} \\
\hline White & & & & & \\
\hline Hispanic & & & & & \\
\hline Black & & & & & \\
\hline Asian & & & \multicolumn{3}{|l|}{ Substance Use Disorder } \\
\hline Highest Education & & & Opioid Use Disorder & 62 & $47 \%$ \\
\hline High School Degree & 14 & $10 \%$ & Alcohol Use Disorder & 30 & $23 \%$ \\
\hline Associates Degree & 19 & $15 \%$ & Sedative-Hypnotic Use Disorder & 21 & $16 \%$ \\
\hline College & 77 & $59 \%$ & None & 18 & $14 \%$ \\
\hline Advanced Degree & 21 & $16 \%$ & \multirow{2}{*}{$\begin{array}{l}\text { Number of Patients with Two or More Substance } \\
\text { Use Disorders }\end{array}$} & \multirow[t]{2}{*}{13} & \multirow[t]{2}{*}{$10 \%$} \\
\hline Chronic Pain (in Years) (SD) & \multicolumn{2}{|c|}{ II.8 (9.1) } & & & \\
\hline Initial Primary Pain Diagnosis & & & Current Tobacco Usage & & \\
\hline Musculoskeletal-Axial & 70 & $53 \%$ & Yes & 8 & $6 \%$ \\
\hline Musculoskeletal-Joint/Limb & 24 & $19 \%$ & No & 143 & $94 \%$ \\
\hline Neuropathic & 15 & $10 \%$ & & & \\
\hline Headache & 9 & $7 \%$ & & & \\
\hline Abdominal & 7 & $5 \%$ & & & \\
\hline Facial & 4 & $3 \%$ & & & \\
\hline Genital & 1 & $1 \%$ & & & \\
\hline $\begin{array}{l}\text { Number of Patients with Two or More Pain } \\
\text { Conditions }\end{array}$ & 46 & $35 \%$ & & & \\
\hline
\end{tabular}

Abbreviations: SD, standard deviation; N, sample size; NOS, not otherwise specified. 
admission and discharge. Scores for the BPI-SF range can from 0 (No pain/Does not interfere) to 10 , where on each sub-scale, pain severity and interference, questions were aggregated. As seen in Table 2, on admission to the CPRC program, patients averaged a pain severity score of 6.2 $(\mathrm{SD}=0.4)$, and a pain interference score of $6.5(\mathrm{SD}=1.2)$ $(\mathrm{p}<0.01)$. On discharge, mean pain severity and interference scores dropped, respectively, to $4.5(\mathrm{SD}=1.7)$ and 3.5 $(\mathrm{SD}=0.13)$ demonstrating a significant difference between admission and discharge using a pair-sampled $t$-test $(\mathrm{p}=.012)$. A significant change was seen when evaluating total pain catastrophe scores at admission $(\mathrm{M}=29.4$, $\mathrm{SD}=6.2)$ to discharge $[(\mathrm{M}=13.9, \mathrm{SD}=4.5), \mathrm{t}(68)=4.9$, $\mathrm{p}<0.01]$. A Pair-sampled $t$-test evaluated the differences between admission and discharge across sub-factors of the CPCI which indicated a significant difference for guarding ( $<<.001)$; asking $(\mathrm{p}=.018)$; exercise $(\mathrm{p}<.001)$; relaxation ( $\mathrm{p}<.001)$; and pacing $(\mathrm{p}=.024)$, with each changing in a direction favorable for pain management.

\section{Depression and Anxiety}

As seen in Table 2, rating scales on depression measured by the Beck Depression Inventory II (BDI-II) and anxiety measured by Beck Anxiety Inventory (BAI) were administered at admission and discharge of the 28-day program. Initial depression scores $(\mathrm{M}=27.9, \mathrm{SD}=4.7)$ indicated a moderate level of depression; at completion of the

Table 2 Average Scores Differences Between Admission and Discharge

\begin{tabular}{|l|l|l|l|l|l|}
\hline \multirow{2}{*}{ Assessments } & \multicolumn{2}{|c|}{ Admission } & \multicolumn{2}{l|}{ Discharge } & \multirow{2}{*}{ P-value } \\
\cline { 2 - 5 } & M & SD & M & SD & \\
\hline Brief Pain Inventory & & & & & \\
Pain Severity & 6.2 & 0.4 & 4.5 & 1.7 & 0.01 \\
Pain Interference & 6.5 & 1.2 & 3.5 & 0.1 & 0.012 \\
Pain Catastrophizing Total & 29.4 & 6.2 & 13.9 & 4.5 & $<.001$ \\
\hline CPCI & & & & & \\
Guarding (IFS) & 56.2 & 2.5 & 43.4 & 1.2 & $<.001$ \\
Resting (IFS) & 54.7 & 0.1 & 48.9 & 1.7 & 0.15 \\
Asking for assistance (IFS) & 50.5 & 1.1 & 44.4 & 1.6 & 0.018 \\
Exercise (WFC) & 48.3 & 1.4 & 59.6 & 0.2 & $<.001$ \\
Relaxation (WFC) & 52.6 & 0.7 & 60.3 & 1.3 & $<.001$ \\
Pacing (WFC) & 47.8 & 0.2 & 52.7 & 0.9 & 0.024 \\
Coping (WFC) & 51.1 & 0.4 & 55.6 & 1.3 & 0.23 \\
Seeking (WFC) & 55.8 & 1.1 & 57.2 & 0.9 & 0.08 \\
Beck Depression Inventory & 27.9 & 4.7 & 9.8 & 2.3 & $<.001$ \\
Beck Anxiety Inventory & 24.9 & 6.1 & 12.8 & 1.4 & 0.001 \\
\hline
\end{tabular}

Abbreviations: $\mathrm{M}$, mean; SD, standard deviation; $\mathrm{CPCl}$, Chronic Pain Coping Inventory; IFS, illness-focused coping; WFC, wellness-focused coping. program, scores were significantly decreased to minimal depression levels $(\mathrm{M}=9.8, \mathrm{SD}=2.3)$. Differences between the admission and discharge depression values were highly significant $(\mathrm{p}<.001)$. A similar reduction was noted for anxiety. On admission, anxiety scores were moderately severe $(\mathrm{M}=24.9, \mathrm{SD}=6.1)$ and upon completion the average scores indicated mild anxiety $(\mathrm{M}=12.8, \mathrm{SD}=1.4)$ exhibiting a significant difference $(\mathrm{p}=.001)$.

\section{Opioid Management}

Of 114 patients for whom complete admission and discharge data on opioid use were available, $72 \%(n=82)$ were being prescribed opioids for pain management at the time of admission at an average admitting dose of 141 MME per day. Specific opioids, number of users, and mean doses on admission and discharge are shown in Table 3. Among patient using opioids on admission, at the time of discharge $37 \%$ had been tapered off all opioids and elected to stay off, $43 \%$ were transitioned to buprenorphine (one patient to methadone) for treatment of opioid use disorder (OUD) and for incidental effects on pain, and $20 \%$ continued on analgesic opioids at a mean discharge dose of 71 MME. The mean dose of opioids on admission for those who were transitioned to

Table 3 Admission and Discharge Opioid Medications

\begin{tabular}{|c|c|c|}
\hline \multicolumn{3}{|l|}{ Admission } \\
\hline Prescription & Frequency & $\begin{array}{l}\text { Average Dosage } \\
\text { (per Day) }\end{array}$ \\
\hline Buprenorphine/naloxone & 1 & $24 \mathrm{mg}$ \\
\hline Fentanyl transdermal & 3 & $54 \mathrm{mcg}$ \\
\hline Hydrocodone & 2 & $23 \mathrm{mg}$ \\
\hline Hydromorphone & 7 & $32 \mathrm{mg}$ \\
\hline Morphine sulfate & 8 & $82 \mathrm{mg}$ \\
\hline Methadone & 6 & $65 \mathrm{mg}$ \\
\hline Hydrocodone/acetaminophen & 5 & $10 \mathrm{mg}$ \\
\hline Oxycodone & 30 & $90 \mathrm{mg}$ \\
\hline Oxycodone/acetaminophen & 4 & $10 / 325 \mathrm{mg}$ \\
\hline Tramadol & 11 & $143 \mathrm{mg}$ \\
\hline Oxymorphone & 5 & $72 \mathrm{mg}$ \\
\hline \multicolumn{3}{|l|}{ Discharge } \\
\hline Prescription Opioid & Frequency & $\begin{array}{l}\text { Average Dosage } \\
\text { (per Day) }\end{array}$ \\
\hline Buprenorphine/naloxone & 35 & $15 \mathrm{mg}$ \\
\hline Methadone & 1 & $78 \mathrm{mg}$ \\
\hline Morphine sulfate & 2 & $35 \mathrm{mg}$ \\
\hline Tramadol & 4 & $50 \mathrm{mg}$ \\
\hline Oxycodone/acetaminophen & 2 & $5 / 325 \mathrm{mg}$ \\
\hline Oxycodone & 8 & $55 \mathrm{mg}$ \\
\hline
\end{tabular}


MAT for OUD was 207, for those off of all opioid's admission MME was 115 and for those continuing on opioids for analgesia, admission MME was 85. Significance was demonstrated between admissions and discharge $(\mathrm{p}<.001)$ of the overall sample and between opioid discharge groups $(\mathrm{p}<.001)$.

\section{Discussion}

The current chart review examined the impact of an interdisciplinary residential treatment program that promotes self-care using behavioral psychotherapies and movement therapies, as well as adjustment of medications, on changes in pain, pain interference, co-occurring mental health diagnoses, and on use of opioid medications. The review demonstrated that treatment was associated with significant reductions in pain and pain interference as well as highly significant reductions in anxiety and depression and highly significant improvements in pain coping. At the same time, there was areduction in reliance on opioids for pain relief with $80 \%$ of patient either entirely discontinuing opioids $(37 \%)$ or transitioning to opioid agonist treatment for opioid use disorder (43\%).

Our findings with respect to the association of opioid doses on admission with opioid management deserve mention. It is of note that patients ultimately prescribed buprenorphine for OUD were on significantly higher mean doses of opioids on admission than those who tapered off of opioids. This is consistent with the observations that higher doses opioid therapy of pain can be associated with opioid use disorders. ${ }^{22,32}$ Perhaps more interesting, however, is that those who continued on analgesic opioids at discharge were admitted on significantly lower mean doses of opioid than those who discontinued opioids (many of whom reported improved pain with taper off of opioids though we did not track these numbers) or who were transitioned to buprenorphine for OUD. This resonates with the observation that a subset of individuals on lower dose opioid therapy long term may experience continued analgesia with opioid use without developing misuse, hyperalgesia or other negative outcomes of use. ${ }^{20}$ However, long-term follow-up of this or similar groups to examine persistence of analgesia, types of pain, comorbidities, function and other variables would be necessary to fully support the observations.

The current findings are not surprising given that evidence-based interventions including CBT, ACT, mindfulness, and movement therapies have independently demonstrated effectiveness in treatment of pain, of anxiety, of depression and of substance use disorders. ${ }^{10,33-35}$ However, our findings add credence to the understanding that integrated use of these approaches can be tailored to treat all components of the combined triad of pain, substance misuse and co-occurring mood disorders simultaneously; that is, it is possible to address co-occurring pain, anxiety, depression and SUDs as a constellation of concerns in an integrated manner using a common set of therapies. Combining these in an intensive residential setting had the added value of collaboration with others with similar challenges to share in problem-solving and development of personal strategies to reduce pain and other symptoms and to improve function. It also reduced social isolation which is a common problem for patients with chronic pain and promoted evolution of interpersonal skills within the context of chronic pain. Further research is needed to advance the effectiveness and optimize the time, cost and resource efficiency of interdisciplinary care in managing this constellation of intersecting chronic pain, substance misuse and mental health disorders in different settings since access to such intensive treatment is limited. It should be noted however, that scant evidence currently available supports a view that investment in interdisciplinary care of chronic pain can yield long term cost savings.

Given the high prevalence of chronic pain co-occurring with mental health and substance use disorders, it is critical to seek more accessible outpatient paradigms that can successfully achieve similar outcomes. This program and similar interdisciplinary programs ${ }^{36}$ have engaged patients in intensive, daily, several week periods of care which is not a paradigm that can realistically be made available to all persons with chronic pain and co-occurring disorders. ${ }^{37}$ A recent study examined three care paradigms offering different intensities of rehabilitative care for chronic low back pain and found that all reduced work sick leave taken in the ensuing 12 months and that there were no differences in quality of life, sociability or personal beliefs between patients completing the different treatment intensities. Intensive residential care is not a realistic model for all patients, ${ }^{38}$ given the high costs to individuals and/or third parties. ${ }^{39}$ However, combinations of these integrated approaches are likely necessary to achieve similar outcomes. $^{40,41}$ Further research is needed to help determine which treatments, at what intensities, and for what durations, are necessary to achieve satisfactory outcomes in terms of chronic pain and co-occurring mood and substance use to expand access and reduce costs and life disruption associated with treatment. 
The determination of efficacy in chronic pain treatment is challenging due to the multiple variables involved in pain and pain treatment, including both co-occurring conditions that contribute to the experience of pain and simultaneous treatments provided to address pain and other symptoms, as well as due to the subjective nature of the experience. Farrar et $\mathrm{al}^{42}$ emphasized that effective treatment is apparent when clinical improvement has been demonstrated. While our study demonstrated clinical improvement in mood, pain, pain interference and pain coping in the context of comprehensive interdisciplinary care, it could not parse which elements of interdisciplinary care at what doses are essential to effective treatment.

\section{Limitations}

There were a number of methodological limitations within the retrospective chart review. First, while this study demonstrates that pain and associated symptoms can be improved, pain interference with function reduced and medication reliance reduced through intensive interdisciplinary residential treatment, it does not indicate whether these improvements can be sustained over time in the individual's natural home environment which is the overall goal of treatment. Unfortunately, the treatment system did not generate adequate post-treatment data to identify pain, mood and substance-related changes over time post-discharge.

Second, all treatments were provided in the context of a clinical program that was not prospectively designed to generate research data which likely resulted in variability of treatment inputs. While treatment was standardized in terms of thematic content offered across the four-week period and in terms of general therapeutic approaches, treatment interventions were not formally manualized or uniform across providers and patients and no measures of fidelity to the various treatment paradigms were performed. Rather, experienced psychologists and social workers with training variously in CBT, ACT and/or mindfulness-based stress reduction, offered group and individual treatment, counseling and education in defined topic areas with identified goals, individualized to patient need. Similarly, for the physical component of the program experienced registered physical therapists provided individualized PT and oversight of independent exercise programs tailored to each patient. Additional therapeutic interventions such as art therapy, yoga, qi gong and some meditation groups were variable in content and frequency. In contrast, prospective clinical studies of pain interventions designed to study specific research questions usually more carefully define and control treatment inputs.
Third, while admissions staff made efforts to record as accurate data as possible regarding opioids and other medication use prior to admission using multiple sources of information, actual opioids and opioid doses used by individual patients prior to admission may not be perfectly accurate. Inaccuracies could impact the validity of our observations regarding correlations between admission opioid doses and subsequent opioid management.

Finally, when extracting and reviewing clinical data regarding patient experience of trauma, inconsistencies were noted in the charts that lead to incomplete data related to relevant clinical issues. For example, multiple sources of trauma information were noted, including query on admission regarding lifetime experience of "trauma", medical records indicating major traumatic injuries, and subsequent documentation of history of childhood or adult sexual, physical or emotional trauma in clinical notes. Given these inconsistencies, it was not possible to provide analysis of trauma as a variable shaping outcome for this current review.

\section{Conclusions}

Patients with chronic pain and co-occurring mental health and substance disorders experienced both significant reductions in pain, anxiety, depression and pain interference related to enjoyment of life and activities, and improved coping with residual pain all while eliminating or reducing opioid reliance through an intensive, residential, four-week interdisciplinary pain program aimed at engaging them in self-care. Core treatment approaches included CBT, ACT, mindfulness training, physical therapy and exercise with additional therapeutic opportunities including yoga, art therapy, and meditation groups among others. Research is needed to determine which of these treatment approaches, in what combinations, and at what doses are critical to chronic pain management success to in order to develop more time and cost-effective delivery of care.

\section{Acknowledgments}

We would like to deeply thank Michael Brennan, MD for his contributions to the CPRC program.

\section{Disclosure}

All authors report no conflicts of interest in this work.

\section{References}

1. Naushad N, Dunn LB, Munoz RF, Leykin Y. Depression increases subjective stigma of chronic pain. J Affect Disord. 2018;229:456-462. doi:10.1016/j.jad.2017.12.085 
2. Gaskin DJ, Richard P. The economic costs of pain in the United States. J Pain. 2012;13(8):715-724. doi:10.1016/j.jpain.2012.03.009

3. Hilton L, Hempel S, Ewing BA, et al. Mindfulness meditation for chronic pain: systematic review and meta-analysis. Ann Behav Med. 2017;51(2):199-213. doi:10.1007/s12160-016-9844-2

4. Bonica JJ, Hoffman JF. The management of pain with special emphasis on the use of analgesic blocks in diagnosis, prognosis, and therapy. Anesth Analg. 1954;34(5):57-58.

5. Treede RD, Rief W, Barke A, et al. A classification of chronic pain for ICD-11. Pain. 2015;156(6):1003-1007. doi:10.1097/j.pain.000 0000000000160

6. Nahin RL. Estimates of pain prevalence and severity in adults: United States, 2012. J Pain. 2015;16(8):769-780. doi:10.1016/j. jpain.2015.05.002

7. Asmundson GJ, Katz J. Understanding the co-occurrence of anxiety disorders and chronic pain: state-of-the-art. Depress Anxiety. 2009;26 (10):888-901. doi:10.1002/da.20600

8. Crofford LJ. Psychological aspects of chronic musculoskeletal pain. Best Pract Res Clin Rheumatol. 2015;29(1):147-155. doi:10.1016/j. berh.2015.04.027

9. Yalcin I, Barrot M. The anxiodepressive comorbidity in chronic pain. Curr Opin Anaesthesiol. 2014;27(5):520-527. doi:10.1097/ACO.00 00000000000116

10. Barry DT, Glenn CP, Hoff RA, Potenza MN. Group differences in pain interference, psychiatric disorders, and general medical conditions among Hispanics and whites in the U.S. general population. Psychiatry Res. 2017;258:337-343. doi:10.1016/j.psychres.2017.08.049

11. Pade PA, Cardon KE, Hoffman RM, Geppert CM. Prescription opioid abuse, chronic pain, and primary care: a co-occurring disorders clinic in the chronic disease model. J Subst Abuse Treat. 2012;43 (4):446-450. doi:10.1016/j.jsat.2012.08.010

12. Worley MJ, Heinzerling KG, Shoptaw S, Ling W. Pain volatility and prescription opioid addiction treatment outcomes in patients with chronic pain. Exp Clin Psychopharmacol. 2015;23(6):428-435. doi: $10.1037 /$ pha0000039

13. Surah A, Baranidharan G, Morley S. Chronic pain and depression. Continuing Educ Anaesth Critical Care Pain. 2014;14(2):85-89. doi:10.1093/bjaceaccp/mkt046

14. Alsaadi SM, McAuley JH, Hush JM, et al. Poor sleep quality is strongly associated with subsequent pain intensity in patients with acute low back pain. Arthritis Rheumatol. 2014;66(5):1388-1394. doi:10.1002/art.38329

15. Loeser J, Turk D. Multidisciplinary pain management. Sem Neurosurg. 2004;15(01):13-29. doi:10.1055/s-2004-830011

16. Turk DC, Stieg RL. Chronic pain: the necessity of interdisciplinary communication. Clin J Pain. 1987;3(3):163-167. doi:10.1097/ 00002508-198703000-00008

17. Gatchel RJ, McGeary DD, McGeary CA, Lippe B. Interdisciplinary chronic pain management: past, present, and future. Am Psychol. 2014;69(2):119-130. doi:10.1037/a0035514

18. Chou R, Turner JA, Devine EB, et al. The effectiveness and risks of long-term opioid therapy for chronic pain: a systematic review for a national institutes of health pathways to prevention workshop. Ann Intern Med. 2015;162(4):276-286. doi:10.7326/M14-2559

19. Huffman KL, Rush TE, Fan Y, et al. Sustained improvements in pain, mood, function and opioid use post interdisciplinary pain rehabilitation in patients weaned from high and low dose chronic opioid therapy. Pain. 2017;158(7):1380-1394. doi:10.1097/j.pain.0000 000000000907

20. Dowell D, Haegerich TM, Chou R. CDC guideline for prescribing opioids for chronic pain United States, 2016. MMWR Recomm Rep. 2016;65(1):1-49. doi:10.15585/mmwr.rr6501e1

21. Elsesser K, Cegla T. Long-term treatment in chronic noncancer pain: results of an observational study comparing opioid and nonopioid therapy. Scand J Pain. 2017;17:87-98. doi:10.1016/j.sjpain.2017. 07.005
22. Volkow N, Benveniste H, McLellan AT. Use and misuse of opioids in chronic pain. Annu Rev Med. 2018;69:451-465. doi:10.1146/ annurev-med-011817-044739

23. Andersen TE, Andersen LA, Andersen PG. Chronic pain patients with possible co-morbid post-traumatic stress disorder admitted to multidisciplinary pain rehabilitation-a 1-year cohort study. Eur J Psychotraumatol. 2014;5.

24. Butler S. The triumvirate of co-morbid chronic pain, depression, and cognitive impairment: attacking this "chicken-and-egg" in novel ways. Scand J Pain. 2017;15:148-149. doi:10.1016/j.sjpain.2017.03.004

25. Gearing RE, Mian IA, Barber J, Ickowicz A. A methodology for conducting retrospective chart review research in child and adolescent psychiatry. J Can Acad Child Adolesc Psychiatry. 2006;15 (3):126-134.

26. Cleeland CS, Ryan KM. Pain assessment: global use of the brief pain inventory. Ann Acad Med Singapore. 1994;23(2):129-138.

27. Krebs EE, Bair MJ, Damush TM, Tu W, Wu J, Kroenke K. Comparative responsiveness of pain outcome measures among primary care patients with musculoskeletal pain. Med Care. 2010;48 (11):1007-1014. doi:10.1097/MLR.0b013e3181 eaf835

28. Beck AT, Steer RA, Brown GK. BDI-II: Beck Depression Inventory Manual. 2nd. ed, Antonio S. TX:Psychological Corporation; 1996

29. Beck AT, Epstein N, Brown G, Steer RA. An inventory for measuring clinical anxiety: psychometric properties. J Consult Clin Psychol. 1988;56(6):893-897. doi:10.1037/0022-006X.56.6.893

30. Sullivan MJL, Bishop SR, Pivik J. The pain catastrophizing scale: development and validation. Psychol Assess. 1995;7(4):524-532. doi:10.1037/1040-3590.7.4.524

31. Romano JM, Jensen MP, Turner JA. The chronic pain coping inventory-42: reliability and validity. Pain. 2003;104(1):65-73. doi:10.1016/S0304-3959(02)00466-9

32. Kaye AD, Jones MR, Kaye AM, et al. Prescription opioid abuse in chronic pain: an updated review of opioid abuse predictors and strategies to curb opioid abuse: part 1. Pain Physician. 2017;20 (2S):S93-S109. doi:10.36076/ppj.2017.s111

33. Bakhshani NM, Amirani A, Amirifard H, Shahrakipoor M. The effectiveness of mindfulness-based stress reduction on perceived pain intensity and quality of life in patients with chronic headache. Glob J Health Sci. 2015;8(4):142-151. doi:10.5539/gjhs.v8n4p142

34. Barry DT, Beitel M, Cutter CJ, et al. An evaluation of the feasibility, acceptability, and preliminary efficacy of cognitive-behavioral therapy for opioid use disorder and chronic pain. Drug Alcohol Depend. 2019;194:460-467. doi:10.1016/j.drugalcdep.2018.10.015

35. McCracken LM, Velleman SC. Psychological flexibility in adults with chronic pain: a study of acceptance, mindfulness, and values-based action in primary care. Pain. 2010;148(1):141-147. doi:10.1016/j.pain.2009.10.034

36. Stanos S. Focused review of interdisciplinary pain rehabilitation programs for chronic pain management. Curr Pain Headache Rep. 2012;16(2):147-152. doi:10.1007/s11916-012-0252-4

37. Bujak BK, Regan E, Beattie PF, Harrington S. The effectiveness of interdisciplinary intensive outpatient programs in a population with diverse chronic pain conditions: a systematic review and meta-analysis. Pain Manag. 2019;9(4):417-429. doi:10.2217/pmt-2018-0087

38. Lynch RT, Agre J, Powers JM, Sherman J. Long-term follow-up of outpatient interdisciplinary pain management with a no-treatment comparison group. Am J Phys Med Rehabil. 1996;75(3):213-222. doi:10.1097/00002060-199605000-00014

39. Mahrer NE, Gold JI, Luu M, Herman PM. A cost-analysis of an interdisciplinary pediatric chronic pain clinic. J Pain. 2018;19 (2):158-165. doi:10.1016/j.jpain.2017.09.008

40. Ronzi Y, Roche-Leboucher G, Begue C, et al. Efficiency of three treatment strategies on occupational and quality of life impairments for chronic low back pain patients: is the multidisciplinary approach the key feature to success? Clin Rehabil. 2017;31(10):1364-1373. doi: $10.1177 / 0269215517691086$ 
41. Petit A, Roche-Leboucher G, Bontoux L, et al. Effectiveness of three treatment strategies on occupational limitations and quality of life for patients with non-specific chronic low back pain: is a multidisciplinary approach the key feature to success: study protocol for a randomized controlled trial. BMC Musculoskelet Disord. 2014;15:131. doi:10.1186/ $1471-2474-15-131$
42. Farrar JT, Young JP, LaMoreaux L, Werth JL, Poole MR. Clinical importance of changes in chronic pain intensity measured on an 11-point numerical pain rating scale. Pain. 2001;94(2):149-158. doi:10.1016/S0304-3959(01)00349-9

\section{Publish your work in this journal}

The Journal of Pain Research is an international, peer reviewed, open access, online journal that welcomes laboratory and clinical findings in the fields of pain research and the prevention and management of pain. Original research, reviews, symposium reports, hypothesis formation and commentaries are all considered for publication. The manuscript

Submit your manuscript here: https://www.dovepress.com/journal-of-pain-research-journa management system is completely online and includes a very quick and fair peer-review system, which is all easy to use. Visit http:// www.dovepress.com/testimonials.php to read real quotes from published authors. 